\title{
Effects of dietary-fish-oil feeding on muscle growth and damage in the rat
}

\author{
BY M. J. JACKSON, J. ROBERTS AND R. H. T. EDWARDS \\ Department of Medicine, University of Liverpool, PO Box 147, Liverpool L69 3BX
}

(Received 30 December 1987 - Accepted 25 April 1988)

1. Giving diets containing $100 \mathrm{~g}$ fully-refined, non-hydrogenated fish oil $/ \mathrm{kg}$ to rats caused substantial modification of skeletal-muscle-membrane fatty acid composition compared with control animals fed on an equivalent diet containing $100 \mathrm{~g}$ maize oil $/ \mathrm{kg}$.

2. Total muscle arachidonic acid $(20: 4 \omega 6)$ was reduced from 138 (so 25$) \mathrm{mg} / \mathrm{g}$ total fatty acids to 15 (SD 2) $\mathrm{mg} /$ $\mathrm{g}$ and phospholipid arachidonic acid content showed equivalent changes.

3. Reduction in muscle arachidonic acid content had no influence on the growth of individual muscles.

4. Variation in muscle fatty acid composition exacerbated the response of muscle to calcium-induced damage assessed by efflux of intracellular creatine kinase $(E C$ 2.7.3.2).

5. It is concluded that metabolites of arachidonic acid are unlikely to be primary controlling factors of muscle growth or specific mediators of muscle sarcolemmal damage leading to enzyme efflux.

Metabolites of arachidonic acid $(20: 4 \omega 6)$ have recently been implicated in the control of muscle protein metabolism (Reeds \& Palmer, 1986) and in the mechanisms by which loss of cell viability occurs in damaged muscle cells (Jackson et al. 1987). In particular, prostaglandin $\mathrm{E}_{2}$ has been proposed as playing a major role in the regulation of protein degradation in muscle (Rodemann et al. 1982) and prostaglandin $F_{2 \alpha}$ has been proposed as being a regulator of protein synthesis rates (Smith et al. 1983; Reeds \& Palmer, 1986). Our previous studies of the mechanisms underlying intracellular enzyme efflux from damaged skeletal muscle have also demonstrated a release of prostaglandins during this process, and inhibitor studies suggest that products of the activity of lipoxygenase enzymes may be mediators of the damaging process (Jackson et al. 1987).

Arachidonic acid is the precursor of the 2 series of prostaglandins and a substrate for lipoxygenase enzymes, and the amount present in membranes is ultimately dependent on the dietary intake of the fatty acid and its precursors. Modification of the dietary fatty acid intake might, therefore, significantly influence the rate of muscle protein deposition (and hence muscle growth) and modify the response of skeletal muscle to damaging stress.

Dietary modification of the fatty acid composition of plasma and platelets has been extensively examined in both animals and man (for review, see Herold \& Kinsella, 1986), and may have substantial effects on haemodynamic indices in man (Woodcock et al. 1984; Norris et al. 1986). The effects of fish oil feeding on the fatty acid composition of liver and heart in experimental animals have been well described (Stubbs \& Smith, 1984) but skeletal muscle has been only sparsely studied from this aspect, although Neudoerffer \& Lea (1967) have reported substantial modification of avian muscle 'neutral' lipid and phospholipid fatty acids by giving diets with different lipid sources.

Fish oils contain substantial amounts of long-chain $\omega 3$ fatty acids which can replace $\omega 6$ fatty acids such as arachidonic acid in membranes. We have therefore attempted to modify skeletal muscle fatty acids in rats using a semi-synthetic diet containing fish oil in order to examine the effect of a reduction in the muscle arachidonic acid content on muscle growth and on the susceptibility of muscle to calcium-overload-induced damage. 
MATERIALS AND METHODS

Groups of three pregnant female Wistar rats were fed on semi-synthetic diets containing either maize oil or fish oil as the lipid source from day 20 of gestation. This dietary regimen was continued until weaning when ten of the weaned female rats were fed on the same diet until 64-65 d of age.

The diet consisted of $(\mathrm{g} / \mathrm{kg})$ : sucrose 657 , casein 180 , maize or fish oil 100 and salt mix 40 . All essential vitamins, minerals and trace elements were provided including vitamin $\mathrm{E}$ ( $20 \mathrm{mg} / \mathrm{kg}$ ). The maize oil used was 'Mazola pure corn oil' (CPC (United Kingdom) Ltd, Clayton House, Esher, Surrey). Fish oil was fully refined, deodorized, non-hydrogenated oil of mixed marine origin (Pura Foods Ltd, Bootle, Merseyside).

At $64-65 \mathrm{~d}$ of age all animals were killed. The soleus and extensor digitorum longus muscles from rats of each group were carefully removed, weighed and soleus muscles were attached to special holders and incubated in vitro in $3.0 \mathrm{ml}$ bicarbonate-buffered Ringer at $37^{\circ}$. The apparatus and conditions used were as previously described (Jones et al. 1983). The incubation was arranged such that two muscles from each group of rats were studied during each experiment. After a 30 min incubation period the medium was exchanged and $25 \mu \mathrm{M}$-calcium ionophore, A23187, an agent known to cause an increased intracellular Ca level leading to both ultrastructural damage (Publicover et al. 1978) and enzyme efflux (Jones et al. 1984) was added to the medium for $30 \mathrm{~min}$. The creatine kinase (EC 2.7.3.2) activity of the incubation media and the muscles was analysed as previously described (Jones et al. 1983).

The gastrocnemius muscles of the rats were extracted with chloroform-methanol using the method of Folch et al. (1957) to extract total lipid. The chloroform layer was separated, dried under nitrogen and divided into two portions. From one portion methyl esters of total muscle fatty acids were prepared by methanolic sodium hydroxide and boron fluorohydride derivatization, while individual phospholipid classes in the other portion were separated by two-dimensional thin-layer chromatography on $100 \times 100 \mathrm{~mm}$ silica gel 60 plates (Merck Laboratories, Darmstadt, West Germany). Chloroform-methanolammonia-water $(40: 22: 2: 3$, by vol.) was the solvent in the first dimension, chloroform-methanol-acetic acid (37.5:20:9, by vol.) was the solvent in the second dimension. Individual phospholipid classes were visualised using iodine vapour, removed from the plate and extracted from the silica using chloroform-methanol. Methyl esters of the phospholipids were then prepared as previously described. Butylated hydroxytoluene ( 50 $\mathrm{mg} / \mathrm{l}$ ) was added to all solvents to prevent autoxidation of fatty acids.

Gas-liquid chromatography of the fatty-acid methyl esters was undertaken on a $2 \mathrm{~m} \times 6$ mm glass column packed with $10 \%$ butane- 1,4 diol succinate on Cromosorb $\mathrm{W}, 80 / 100$ mesh (Phase separations Ltd, Queensferry, Clwyd) at 160-190\%.

All chemicals used were of AnalaR grade or the highest purity available.

Statistical significance of results was assessed using Student's $t$ test, $P>0.05$ being considered non-significant.

\section{RESULTS}

The fatty acid compositions of the fish oil and maize oil used in the present study are

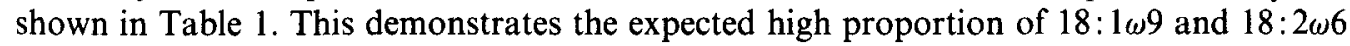
fatty acids in the maize oil and high proportion of longer chain fatty acids in the oil of marine origin.

Unfortunately the gas-liquid chromatographic techniques used were incapable of separating 22:1 from 20:5 fatty acids although previous work suggests that eicosa- 
Table 1. Fatty acid composition of oils used in experimental diets ( $\mathrm{mg} / \mathrm{g}$ total fatty acids from $C_{16}-C_{22}$ )

\begin{tabular}{llll}
\hline Fatty acid & Maize oil & Fish oil \\
\hline $16: 0$ & 87 & 123 \\
$16: 1$ & Trace & 79 \\
$18: 0$ & 14 & 21 \\
$18: 1$ & 329 & 174 \\
$18: 2 \omega 6$ & 551 & 17 \\
$18: 3 \omega 3$ & 15 & 8 \\
$20: 1$ & 4 & 151 \\
$20: 4 \omega 6$ & - & 3 \\
$20: 5 \omega 3 / 22: 1$ & - & 313 \\
$22: 5 \omega 3 / 6$ & - & 26 \\
$22: 6 \omega 3$ & - & 88 \\
\hline
\end{tabular}

Trace, $<1 \mathrm{mg} / \mathrm{g}$.

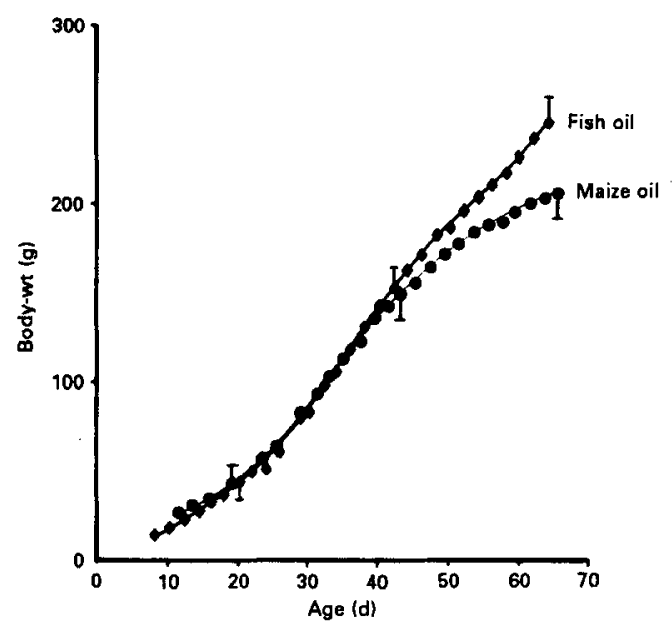

Fig. 1. Growth of rats fed on either maize-oil- $(\boldsymbol{O})$ or fish-oil- $(\bullet)$ supplemented diets. Results are means for ten animals and variation in weights (I SD represented by vertical bars) are only shown at selected points for clarity. For details of diets, see Table 1 and p. 218.

pentaenoic acid would be the major fatty acid in mixed marine oils. It was also not possible to separate $22: 5 \omega 3$ from $22: 5 \omega 6$ fatty acids.

Weaned female rats fed on the fish-oil-supplemented diet were found to grow identically to the maize-oil-supplemented group until approximately day 45 of life, after which the maize-oil-supplemented group grew less rapidly (Fig. 1). On death at $65 \mathrm{~d}$ the major reason for the increased weight of the fish-oil-fed rats appeared to be excessive fat deposition, particularly within the liver. Individual muscles showed no significant difference in weight between the two groups (Table 2).

\section{Muscle fatty acid composition}

The total fatty acid composition of the gastrocnemius muscies from the two groups is shown in Table 3. Significant differences were found between the two groups for almost all the fatty acids analysed and, in particular, large decreases in the contents of linoleic acid 
Table 2. Effect of feeding different oils on body-muscle weights of rats

(Mean values and standard deviations for ten animals)

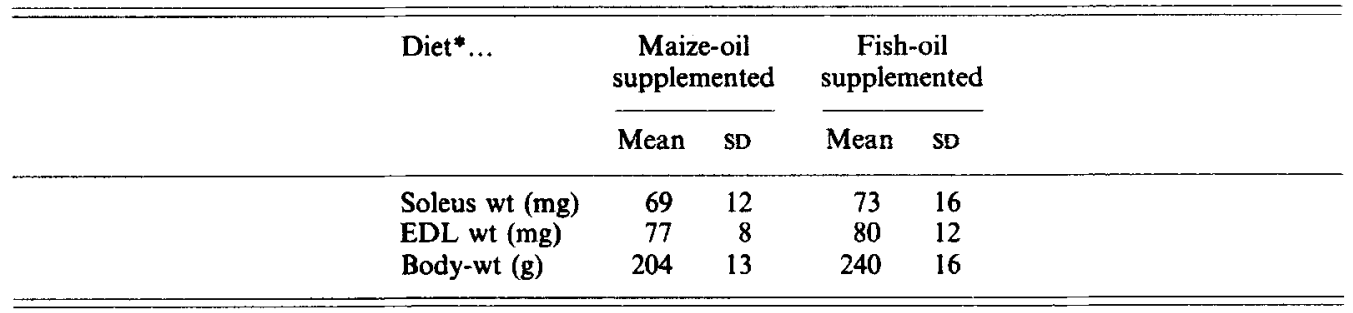

EDL, extensor digitorum longus muscles.

* For details, see Table 1 and p. 218.

Table 3. Total fatty acid composition (mg/g total fatty acids) of gastrocnemius muscles of rats fed on different oils

(Mean values and standard deviations for ten animals)

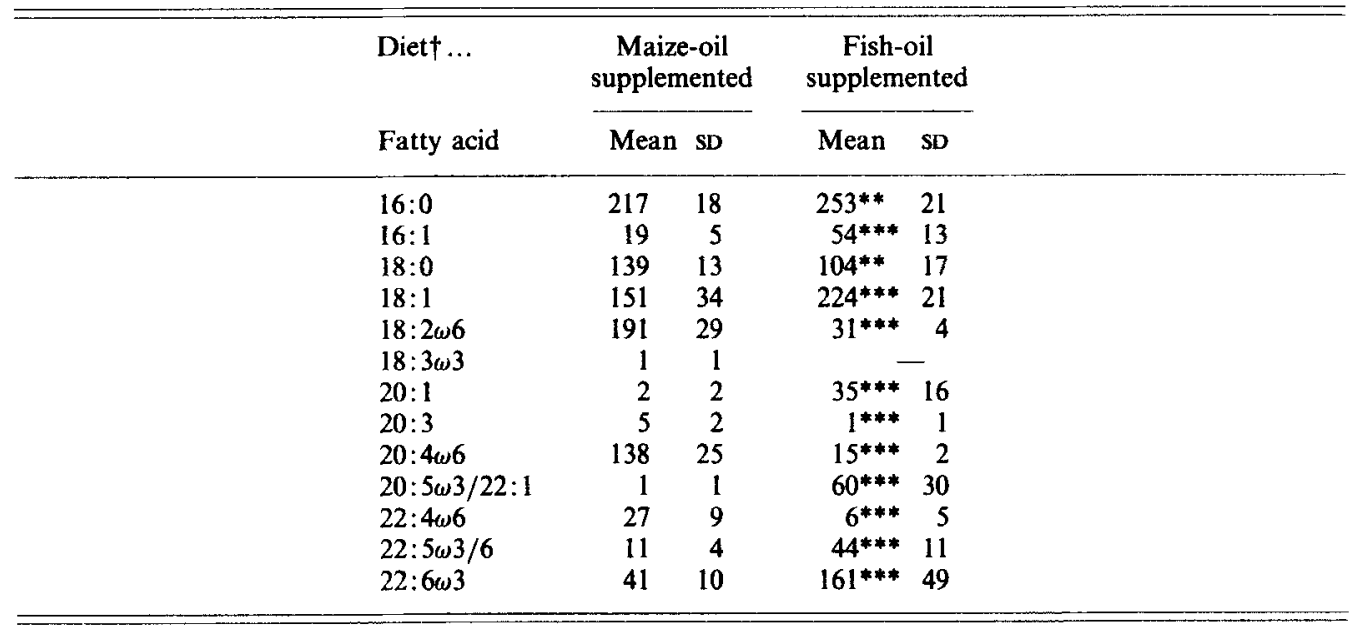

Mean values were significantly different from those for maize-oil-supplemented animals: ${ }^{* *} P<0.01,{ }^{* * *} P<$ 0.001 .

$\dagger$ For details, see Table 1 and p. 218.

$(18: 2 \omega 6)$ and arachidonic acid were seen in the muscle of the fish-oil-fed group, associated with increases in the $18: 1,20: 1,20: 5 \omega 3 / 22: 1,22: 5$ and $22: 6 \omega 3$ fatty acids.

The fatty acid content of the muscle phosphatidyl choline and phosphatidyl ethanolamine (Table 4) showed the same pattern as that found in the total muscle fatty acids, but the results showed considerably more variability. Nevertheless very large and significant decreases in the lineoleic and arachidonic acid contents and significant increases in the 22: $6 \omega 3$ fatty acids were seen in both phospholipids of the fish-oil-fed animals. Other fatty acids showed significant differences only in the phosphatidyl choline fraction.

\section{Response of muscle to Ca ionophore}

The creatine kinase efflux from soleus muscles from both groups of animals is shown in Fig. 2. Muscle weights were equivalent for each group of animals, but treatment of the muscles with the $\mathrm{Ca}$ ionophore $(\mathrm{A} 23187 ; 25 \mu \mathrm{M})$ for $30 \mathrm{~min}$ induced a greater efflux of the cytosolic 
Table 4. Fatty acid composition ( $\mathrm{mg} / \mathrm{g}$ total fatty acids) of individual phospholipids from gastrocnemius muscles of rats fed on different oils

(Mean values and standard deviations for ten animals)

\begin{tabular}{|c|c|c|c|c|}
\hline \multirow[t]{2}{*}{ Diet $† \ldots$} & \multicolumn{2}{|c|}{$\begin{array}{c}\text { Maize-oil } \\
\text { supplemented }\end{array}$} & \multicolumn{2}{|c|}{$\begin{array}{c}\text { Fish-oil } \\
\text { supplemented }\end{array}$} \\
\hline & Mean & SD & Mean & SD \\
\hline \multicolumn{5}{|c|}{ (a) Phosphatidyl choline } \\
\hline $16: 0$ & 431 & 77 & $566^{* *}$ & 93 \\
\hline $16: 1$ & 78 & 39 & $226^{* *}$ & 134 \\
\hline $18: 0$ & 89 & 26 & 66 & 15 \\
\hline $18: 1$ & 65 & 25 & 97 & 58 \\
\hline $18: 2 \omega 6$ & 140 & SI & \multicolumn{2}{|c|}{ Trace*** } \\
\hline $20: 4 \omega 6$ & 129 & 69 & \multicolumn{2}{|l|}{ Trace*** } \\
\hline $20: 5 \omega 3 / 22: 1$ & - & & \multicolumn{2}{|l|}{ Trace } \\
\hline $22: 4 \omega 6$ & 53 & 41 & 68 & 22 \\
\hline $22: 5 \omega 3 / 6$ & - & & $16^{* * *}$ & 4 \\
\hline $22: 6 \omega 3$ & 14 & 7 & $57^{* *}$ & 42 \\
\hline \multicolumn{5}{|c|}{ (b) Phosphatidyl ethanolamine } \\
\hline $16: 0$ & 79 & 24 & 98 & 27 \\
\hline $16: 1$ & 77 & 76 & 147 & 103 \\
\hline $18: 0$ & 302 & 155 & 260 & 82 \\
\hline $18: 1$ & 55 & 20 & 91 & 62 \\
\hline $18: 2 \omega 6$ & 48 & 23 & \multicolumn{2}{|c|}{ Trace*** } \\
\hline $20: 4 \omega 6$ & 158 & 60 & \multicolumn{2}{|l|}{ Trace*** } \\
\hline $20: 5 \omega 3 / 22: 1$ & - & - & \multicolumn{2}{|l|}{ Trace } \\
\hline $22: 5 \omega 3 / 6$ & 58 & 31 & 50 & 16 \\
\hline $22: 6 \omega 3$ & 90 & 56 & $183^{* *}$ & 28 \\
\hline
\end{tabular}

Trace, $<1 \mathrm{mg} / \mathrm{g}$.

Mean values were significantly different from those of maize-oil-supplemented animals: ${ }^{* *} P<0.01,{ }^{* * *} P<$ 0.001 .

† For details, see Table 1 and p. 218.

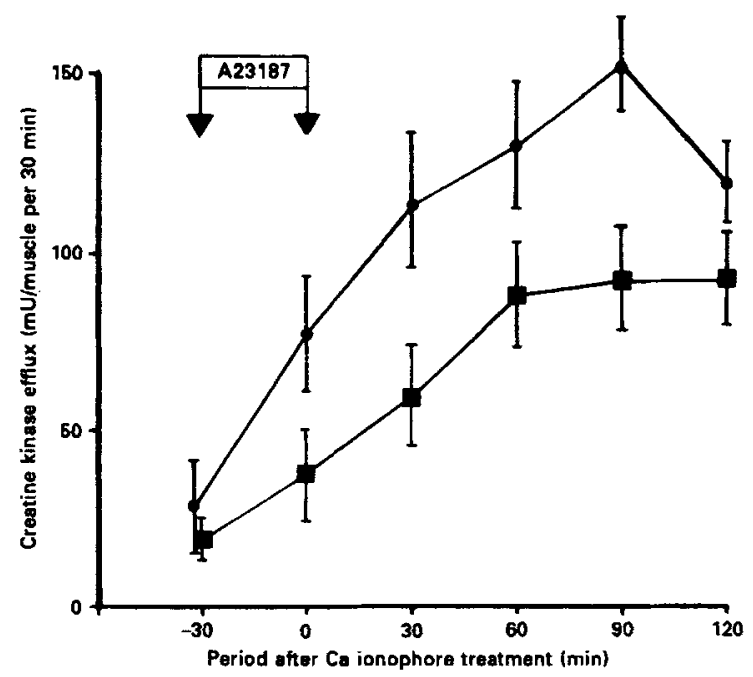

Fig. 2. Creatine kinase (EC 2.7.3.2) efflux from soleus muscles of rats fed on either maize-oil- ( $\square$ ) or fish-oil- (O) supplemented diets. $\downarrow$ Muscles were treated with the calcium ionophore (A23187) for 30 min. Points are means and standard deviations represented by vertical bars for eight muscles. For details of diets, see Table 1 and p. 218. 
enzyme from the muscles of the fish-oil-supplemented animals than from those of the maize-oil-fed group. Preliminary studies demonstrated no significant differences between the total creatine kinase activities of the muscles from the two groups.

\section{DISCUSSION}

Products of the enzymic oxidation of arachidonic acid are important mediators of a number of important biological processes. In particular, in the case of skeletal muscle, prostaglandins $E_{2}$ and $F_{2 \alpha}$ have been implicated in the control of the rates of protein degradation (Rodemann et al. 1982) and protein synthesis (Reeds \& Palmer, 1986) respectively, while inhibitor studies have suggested that products of lipoxygenase $(E C$ 1.13.11.12) activity may be involved in the processes by which loss of cell viability occurs following damaging contractile activity and other stresses (Jackson et al. 1987). Oils derived from marine sources contain a high proportion of long-chain $\omega 3$ fatty acids with relatively small amounts of $\omega 6$ fatty acids and have consequently been extensively used in such nutritional studies (for review, see Herold \& Kinsella, 1986). Previous information on the effects of fish-oil feeding on skeletal muscle fatty acids is sparse, but the results in Tables 3 and 4 indicate a substantial substitution of muscle $\omega 6$ fatty acids with $\omega 3$, which is in agreement with the compositional differences between the two oils used in the semisynthetic diets (Table 1). In particular dramatic reductions in 18:2 $\omega 6$ and arachidonic acid $(20: 4 \omega 6)$ were found in the total muscle fatty acids and in the phospholipid fractions, while increases in the $20: 5 \omega 3 / 22: 1$ and $22: 6 \omega 3$ occurred. The thin-layer chromatographic method used failed to achieve complete separation of phosphatidyl inositol from other lipids in all muscle samples and results for the fatty acid analysis of this phospholipid are therefore not presented. However, the limited findings we have suggest that reduction of the

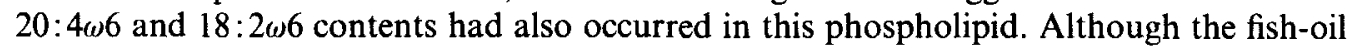
feeding induced dramatic change in total muscle fatty acid composition we have no evidence that all subcellular membranes were modified to a similar extent, but the magnitude of the changes in total muscle composition suggest that all major subcellular membrane systems must have been influenced to some extent.

The origin of the arachidonic acid from which prostaglandins and other 'active' metabolites are formed is the subject of much discussion. Some workers suggest that the arachidonic acid is released from phosphatidyl inositol by a combination of phospholipase $\mathrm{C}$ (EC 3.1.4.3) followed by lipoprotein lipase (diacylglycerol lipase) (EC 3.1.1.34) activity, while others suggest that the liberation is due to the action of phospholipase $A_{2}$ (EC 3.1.1.4) on other phospholipids such as phosphatidyl ethanolamine (for discussion, see Irvine, 1982). Although we were unable to assay prostaglandin efflux from muscles in the present case, previous work suggests that in most tissues changes in the membrane fatty acid content of the extent seen in the muscles of the groups of animals in the present work would induce considerable changes in the formation of prostaglandins of the 2 series and other products of arachidonate oxidation on stimulation (Hornstra, 1985).

The growth of rats fed on the fish-oil-supplemented diet was very similar to those fed on the maize-oil-supplemented diet until approximately $40 \mathrm{~d}$ of age, from which time there was an apparently higher rate of growth in the fish-oil-supplemented rats. Whilst this extra weight gain in the fish-oil groups may have been in part due to a pathological accumulation of fat in this group, the generally similar rates of growth in the two groups and the identical soleus and extensor digitorum longus muscle weights (Table 2) argues against a crucial role of arachidonic acid metabolites in the control of muscle growth such as that proposed by Reeds \& Palmer (1986). It is entirely possible that the apparently normal growth of muscles in the fish-oil-fed group is associated with a change in both protein synthesis and 
degradation rates, with the resultant net rate of protein deposition remaining the same, and we are therefore unable to draw any definite conclusions regarding the effects of fish-oil feeding on muscle protein synthesis or degradation rates. However, recent work from Palmer \& Wahle (1987) argues against this since they have reported that fatty acids of the $\omega 6$ series can stimulate protein synthesis in vitro, but $\omega 3$ fatty acids have no effect. It is interesting that in previous work of Reeds and co-workers (Smith et al. 1983; Reeds \& Palmer, 1986) and Rodemann et al. (1982), no evidence was found of a decrease in unstimulated protein synthesis or degradation rates by inhibition of prostaglandin synthesis, although stimulated rates of both processes were reduced by such inhibitors. If it is assumed that normal growth in rats is analogous to the 'unstimulated' situation in vitro, then the results presented here are in accordance with the in vitro experiments, but it is therefore possible that muscle growth in vivo, acutely stimulated by anabolic agents, etc., may be reduced by fish-oil feeding. Soleus and extensor digitorum longus muscles were measured in these studies as being representative of primarily oxidative and glycolytic muscles respectively.

Previous work on the mechanisms by which damage occurs to skeletal muscle following a number of stresses (e.g. excessive contractile activity or treatment with metabolic inhibitors) indicates that accumulation of intracellular $\mathrm{Ca}$ is a key step in the process (Jones et al. 1984; Claremont et al. 1984) and that this may lead to an activation of phospholipase enzymes (Jackson et al. 1984). Further studies have revealed that a release of prostaglandins $\mathrm{E}_{2}$ and $\mathrm{F}_{2 \alpha}$ accompanies $\mathrm{Ca}$-induced damage to the muscle sarcolemma and that inhibition of lipoxygenase enzymes prevents the efflux of intracellular enzymes (Jackson et al. 1987). The work presented here demonstrates that soleus muscles from the fish-oil-supplemented animals show an exacerbated release of intracellular enzymes following intracellular $\mathrm{Ca}$ overload induced by $\mathrm{Ca}$ ionophore (Fig. 2), suggesting that arachidonic acid metabolites do not mediate this process and implying that leukotrienes $B_{4}, C_{4}$, etc. and similar metabolites are not involved.

This apparent discrepancy between the present findings and the previous work with lipoxygenase inhibitors may possibly be explained by a lack of substrate specificity by lipoxygenase enzymes. Previous workers have shown that mammalian lipoxygenase enzymes can utilize substrates other than arachidonic acid (Fischer et al. 1982; Murphy et al. 1981) and it appears likely that a wide spectrum of substrates can be utilized by these enzymes. Other work from this laboratory (unpublished results) has demonstrated that lipoxygenase enzymes are present in mammalian skeletal muscle, but the enzyme(s) has not yet been isolated and purified. However, muscle may be able to catalyse the peroxidation of a number of different fatty acids and it is possibly these compounds (i.e. polyunsaturated fatty acid hydroperoxides) which mediate the loss of cell viability and efflux of intracellular enzymes following intracellular $\mathrm{Ca}$ overload.

An alternative explanation for the findings, which cannot be discounted, is that the sarcolemmal permeability changes are induced by non-enzymic lipid peroxidation of the membrane fatty acids and that the exacerbated release of enzymes is due to increased peroxidation of the long-chain fatty acids derived from fish oils. All the lipoxygenase inhibitors used in previous studies (Jackson et al. 1987) also have the ability to inhibit nonenzymic lipid peroxidation, but previous studies have demonstrated that many other known inhibitors of the non-enzymic process are without effect in this system (Jackson \& Edwards, 1988).

The authors would like to thank Dr D. Allan of Pura Foods Ltd, Research and Development Centre, Dunnings Bridge Road, Bootle, Merseyside for advice and supply of the fish oil, Dr Anton Wagenmakers for helpful discussions, Miss Linda Horan for 
assistance with the animal feeding and the Muscular Dystrophy Group of Great Britain and Northern Ireland and F. Hoffmann La Roche and Co. for financial support.

\section{REFERENCES}

Claremont, D., Jackson, M. J. \& Jones, D. A. (1984). Journal of Physiology 353, 57P.

Fischer, S., Schacky, C. V., Siess, W., Strasser, T. \& Weber, P. C. (1982). Biochemical and Biophysical Research Communications 120, 907-918.

Folch, J., Lees, M. \& Sloane, G. H. (1957). Journal of Biological Chemistry 226, 497-509.

Herold, P. M. \& Kinsella, J. E. (1986). American Journal of Clinical Nutrition 43, 566-598.

Hornstra, G. (1985). In Advances in Inflammation Research, vol. 10, pp. 1-6 [F. Russo-Marie, editor]. New York: Raven Press.

Irvine, R. F. (1982). Biochemical Journal 204, 3-16.

Jackson, M. J. \& Edwards, R. H. T. (1988). In Reactive Oxygen Species in Chemistry, Biology and Medicine, pp. 197-210 [A. Quintanilla, editor]. New York: Plenum Press.

Jackson, M. J., Jones, D. A. \& Edwards, R. H. T. (1984). European Journal of Clinical Investigation 14, 369-374.

Jackson, M. J., Wagenmakers, A. J. M. \& Edwards, R. H. T. (1987), Biochemical Journal 241, $403-407$.

Jones, D. A., Jackson, M. J. \& Edwards, R. H. T. (1983). Clinical Science 65, 193-201.

Jones, D. A., Jackson, M. J., McPhail, G. \& Edwards, R. H. T. (1984). Clinical Science 66, 317-322.

Murphy, R. C., Pickett, W. C., Culp, B. R. \& Lands, W. E. M. (1981). Prostaglandins 22, 613-622.

Neudoerffer, T. S. \& Lea, C. H. (1967). British Journal of Nutrition 21, 691-714.

Norris, P. G., Jones, C. J. H. \& Weston, M. J. (1986). British Medical Journal 293, 104-105.

Palmer, R. M. \& Wahle, K. W. (1987). Biochemical Journal 242, 615-618.

Publicover, S. J., Duncan, C. J. \& Smith, J. L. (1978). Journal of Neuropathology and Experimental Neurology 37, 544-577.

Reeds, P. J. \& Palmer, R. M. (1986). In Control and Manipulation of Animal Growth, pp. 161--185 [F. P. J. Buttery, N. B. Haynes and D. B. Lindsay, editors]. London: Butterworths.

Rodemann, H. P., Waxman, L. \& Goldberg, A. L. (1982). Journal of Biological Chemistry 257, 8716-8723.

Smith, R. H., Palmer, R. M. \& Reeds, P. J. (1983). Biochemical Journal 214, 153-161.

Stubbs, C. D. \& Smith, A. D. (1984). Biochimica et Biophysica Acta 779, 89-137.

Woodcock, B. E., Smith, E., Lambert, W. H., Jones, W. M., Galloway, J. H., Greaves, M. \& Preston, F. E. (1984). British Medical Journal 288, 592-594. 